\title{
Understanding Consumers Online Impulse Grocery Shopping: A Stimulus Organism Response Framework Approach
}

\author{
Abhishek S Deokule ${ }^{1}$ and Hemant Katole ${ }^{2}$ \\ ${ }^{1} P T V A$ 's Institute of Management, University of Mumbai, India \\ ${ }^{2}$ Department of Management Sciences (PUMBA), Savitiribai Phule Pune University, India
}

\section{ABSTRACT}

This study lays emphasis on the theoretical S-0-R framework also known as the Stimuli-Organism-Response framework to understand the reasons as to why consumers buy grocery products impulsively in the online milieu. The research review throws light on certain environmental cues to know the motives behind impulse buying. The website stimuli being one of the prime factors that govern the attitude of the consumers towards online grocery shopping, their ability to manoeuvre and regulate their emotions and state of mind before indulging in shopping impulsively. There are certain hedonic motives which influences the consumers to shop inadvertently resulting in a positive outcome. Consumer's mood states also define the way in which they assess the buying process subconsciously which urges them to buy on impulse. The paper seeks to understand the utilitarian shopping value and its impact on consumers overall buying tendency. The researcher to better this framework conducted focus group to identify the qualitative parameters which drives impulsiveness and hence the purchase. The environmental cues act a major force and thus creates an overall positive influence toward online shopping. The study unravels startling revelations such as Mood States, Discounts on Premium Brands, Security, Offers, Time, Convenience as the means to buy impulsively.

KEY WORDS: S-0-R FRAMEWORK, HEDONIC SHOPPING, ONLINE IMPULSE, ONLINE GROCERY, URGE TO BUY, IMPULSE BUYING.

\section{INTRODUCTION}

Grocery industry is by far a wide consumer segment which needs to be explored more. An average Indian household spends nearly $50 \%$ of the monthly proceeds on buying groceries be it online or offline. The estimation of Grocery retail in India is approximately $60 \%$ of the country's total market comprising the retail segment. Market Researchers \&t Experts estimate it somewhere around $\$ 500$ billion at present. The likely market can

Biosc Biotech Res Comm P-ISSN: 0974-6455 E-ISSN: 2321-4007

\section{crossef}

Identifiers and Pagination

Year: 2021 Vol: 14 No (5) Special Issue

Pages: $56-60$

This is an open access article under Creative

Commons License Attribn 4.0 Intl (CC-BY).

DOI: $h t t p: / / d x$.doi.org/10.21786/bbrc/14.5/12 across around 800 billion by end of 2022. Online grocery is one such segment within the grocery industry that is booming faster than expected in the current times with a greater market strength. The estimation is roughly around $\$ 550$ million to a little over $\$ 1.75$ billion currently and is expected to cross $\$ 4$ or even much more in the next three to four years.

The e-grocery market is all set to reach the estimated market potential of $\$ 18.2$ bn by 2024. It's not just the about the proportion of the grocery pie that is striking to many online grocery sellers but it is the product assortment and its combination which is lucrative. For every household Groceries are a mainstay and are frequently bought with a higher repurchase intention resulting in a high repeat rate. They are purchased commonly and with a high repeat rate. Customers classically buy them without thinking too much which can be organic when it comes to planned purchase and

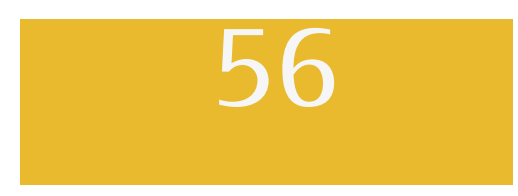


the buying which is not planned is an area of interest to the researchers.

In online retailing perusing the effect of the online environment on human psyche has its roots instilled in Marketing, Consumer Behaviour and Psychology. Stimulus-response theory established a strong interconnectedness between the external environment and human behaviour. Kotler (1973) initially addressed the importance of atmospherics in the offline space as a means of marketing. This concept was further accentuated by Bitner wherein the termed was commonly referred as 'servicescape', which defined all those factors physical in nature that could be monitored and influenced by the organization to enrich the employeecustomer interaction. Bitner (1992, p. 65); postulated that the service encounter or interaction largely is affected by the external physical environment in which the service is delivered. Further studies by Ezeh \&t Harris (2007) defined servicescape which included non-physical components identified as social factors comprising of the ambience referred to as ambient factors, servicescape design.

Lazarus (1998, p. xvii) argued that the stimulus-response theory considers the person as a passive creature who reacts to the stimulation environment that nudges him or her to buy and that the influence of the person on the surrounding environment is ignored explicitly. Consumers are considered as mechanical identities who react to the stimuli and the metaphor used to explain this phenomenon is between a lamp and a power switch. Mehrabian \&t Russell (1974) stated that people behave differently and differ in terms of developing organismic reactions to stimuli, though the influence of external stimuli can't be denied. A person exposed to external stimuli would develop reactions which would eventually lead to behavioural responses as per the S-O-R framework. Arora (1982), Buckley (1991), Donovan Et Rossiter (1994) and Wakefield and Blodgett (1996) studied the S-O-R framework and its implications in the marketing discipline pertaining to consumer behaviour. Research has unravelled various facets of the influence of traditional store environment and its ability to influence consumers to buy on impulse with emphasis on the cognitive and emotional state of mind.

Literature Review: Mehrabian and Russell (1974) suggested an academic cum theoretical framework Stimulus-Organism-Response (S-O-R) which was later refurbished by Jacoby (2002). The foundation sets an academic \& a research base to support the proposed model in our study. There are certain cues in the environment that ignite the emotional as well as cognitive state of mind of an individual which subsequently influences behavioural response or action that eventually would lead to either buying. Donovan and Rositer (1982) corroborated the phenomenon by conducting their own study of the aforesaid framework. The consumer behaviour aspect in Marketing is a very well-defined process and has some of its theory set in the framework. Eroglu et al., (2003) extended the study to computer science, Mollen and Wilson (2010) enumerated the effect of having an engaging website experience whereas Olney et al., (1991) studied its applicability to consumer behaviour.

Rose et al., (2012) suggested recent research and academic advances in the various industries and the consumer buying and allied areas which were corroborated by the research carried out by Reitz (2012). Eroglu et al., (2001) defines three elements in the S-O-R framework which are stimulus, organism, and response. The influence that arouses or is induced within the individual is defined as the stimulus. In the virtual environment which is our prime focus of study the stimulus can be the infrastructure of the online brand community. Mollen and Wilson (2010) suggested few characteristics such as the virtual layout, interactivity, the quality of information, rewards and promotions that can possibly act as a source of trigger. Their study dealt with how online communities have an impact on customer engagement and proves that the factors studied act as significant influencers.

Loureiro and Ribeiro (2011) in their research lay emphasis on the cognitive and affective states which are intermediary customer states. The organism component of the S-0-R framework delves into these intermediary states that demonstrates the various processes a customer subconsciously encounters between the stimuli and behavioural responses of the customers. Eroglu et al., (2001) elucidate the Cognitive bent of mind that represents everything that the mind subconsciously processes such as understanding, assessment, acquisition, information retrieval, retention whereas, Affective state reproduces the emotions like mood states, pleasure, stimulation, excitement exhibited by customers subject to the external environmental stimuli. Loureiro and Ribeiro (2011) studied the effect of customers behavior once exposed to various stimuli which helps them process information in their minds and aids in making meaningful decisions.

Donovan and Rositer (1982) enumerate that cognition and affection are the significant dimensions of engaging customers, and their study claims that customer engagement is the organism element state of the S-O-R framework where the stimuli would play positively with the customers cognitive and affective state of mind making the customer responsive. Bitner (1992) and Eroglu et al., (2001) posited that the response dimension of the S-O-R framework is the consequence in the form of positive attitude exhibited by the customers' or avoidance behaviours. Approach behaviours are positive responses that are revealed by the customers on explicit settings in the form of buying, repeat purchases and constructive word of mouth communications, whereas avoidance behaviours echo the negative communications where the consumers would not like to buy and has no intentions to stay. The response in the form of behavioural outcome can be deemed as attitudinal, thus the study inspects trust and loyalty as a response of customer engagement in online communities. 
Prashar, et al., (2017) studied this concept and applied the theoretical framework to the online buying space. Donovan and Rossiter empirically estimated the effect of retail atmosphere on customers buying decision. Eroglu, et al., (2003) defined the advantage of creating an atmosphere on the Internet and named it as Web atmospherics which briefly explained the positive aspects of designing a website that can attract the attention of the prospective customers while buying online. Review of various related literature postulates that web atmospherics have been conceptualized in many ways viz. on the basis of interface oriented visible cues and the high task vs. low task orientation of atmospheric signs. Prashar, et al., (2017) researched the informative, entertainment and effectiveness of the web atmospherics. The environmental cues of any retail setting can affect either the cognitive or affective states or both and may help the buyer to get a feeling of telepresence in the set-up. i.e., "the persuasive sense of being present in a virtual environment that is mediated'. Novak, et al., (2000) elucidated that online marketer need to focus their attention to make consumers feel as if they are shopping in an offline environment so as to generate positive response.

Manganari et al., (2009) and Mummalaneni (2005) enumerate the factors that is manifested by stimulus in the online shopping domain. Factors like website security, layout of the website, design, online promotions have an effect on the performance of the online stores. The organism element of the framework in the online shopping milieu is the feeling of trust that the consumers associate with the website that reflects both the states viz affective and cognitive of the potential buyer which serves as a transitional stage that results in behavioural outcomes such as trial, repeat purchases, avoidance, etc. Lately, various research scholars have pragmatically applied the SOR framework to unravel the impulsive behaviour of consumers online.

Chang and Chen (2008), Kim and Lennon (2010), Demangeot and Broderick (2016) and Manganari et al., (2009), etc. have studied and explored the phenomenon of online buying laying its foundation on the S-O-R framework. Research ranging from assessing online consumer behaviour, response of consumers, their emotional and behavioural responses to online e-retailers, potential consumers' trust and online purchase intentions, repurchase phenomenon, online web or internet atmosphere termed as webmosphirics which inadvertently affects consumers behaviour online and consumers' interaction and communication with the online retail stores and their consequences.

This study further augments the stimulus-organismresponse (S-O-R) model to include impulse-buying behavior with reference to grocery shopping. The S-O-R framework plays an instrumental role in electronic shopping but has still not unearthed the attention it deserved in the academia particularly when studying about electronic commerce research. The basis of our research is in marketing, consumer behaviour, planned purchases and unplanned buying along with environmental psychology, the impact of virtual atmospheric cues on online impulse-buying behavior and spending have been identified. Their study elaborates on variables such as shopping fun, excitement and unplanned buying coined as impulsiveness thus establishing relationship between categories of atmospheric cues of an online e-tailer such as content of the website, design and layout, and navigation to transition into behavioral variables which are impulse-buying behavior and expenditure or spending. The results show evidences of the validity of the $\mathrm{S}-\mathrm{O}-\mathrm{R}$ model in the milieu of online impulse-buying behavior and show a significant positive correlation of two dimensions of virtual atmospheric cues which are design and navigation of website.

Childers et al., (2001) enumerate the importance of sensory information via the interactive media and emphasise that it is sufficient enough to prove and trust that the online shoppers will enjoy web-shopping using new age media tools for web-shopping. Childers et al. (2001) defined "Webmosphirics" that signifies the internet virtual environment which corresponds to the physical surroundings associated with the retail atmosphere such as graphics, text, pop-up windows, search engine configuration, audio, colour scheme, streaming video, product assortment displays and grouping of products that may lead to impulse buying online.

Ramus and Nielsen (2005) reckon that online shoppers perceive internet grocery shopping an advantage when compared to traditional grocery shopping in terms of convenience, product range and price. Disadvantages, which could act as psychological barriers, are, for instance, the risk of receiving mediocre quality groceries and the loss of the frivolous aspect of grocery shopping. Morganosky and Cude (2000) described convenience and saving time as the main motive for buying groceries online but referred to physical or constraint issues that made it inconvenient for grocery shoppers to shop at grocery stores.

\section{METHODOLOGY}

Qualitative Research in form of focus group discussions were conducted in Mumbai Suburban \& Pune City

a. 8 females belonging to the age group of 25-40 years

b. 8 males belonging to the age group of 25-40 years

c. 8 males $\mathrm{Et}$ females belonging to the age group 40-55 years.

The qualitative research was conducted with respondents who bought groceries online at least twice a month and belonged to higher income group or Rs.50000 and more. During the discussion it emerged:

1. Big discount / sale days

2. Discount on premium brands

3. Combo offers with regular product

4. Notifications for discounts 
5. Offers on big pack

6. A tempting recipe offline

7. Someone appreciates a new brand

8. Bored of eating regular food

9. In a mood to celebrate

10. See a rare / exotic ingredient

11. Traditional dishes of other states

12. Product not available earlier

13. Traditional dish elders prepared

14. Tempting dish on Instagram

15. A tempting recipe online

16. Notifications for new launch

17. A new variant of known brand

18. Brand advertisement offline

19. Tempting display

20. Popup / banner on other apps

Figure 1: Online impulse buying grocery shopping based on S-O-R framework

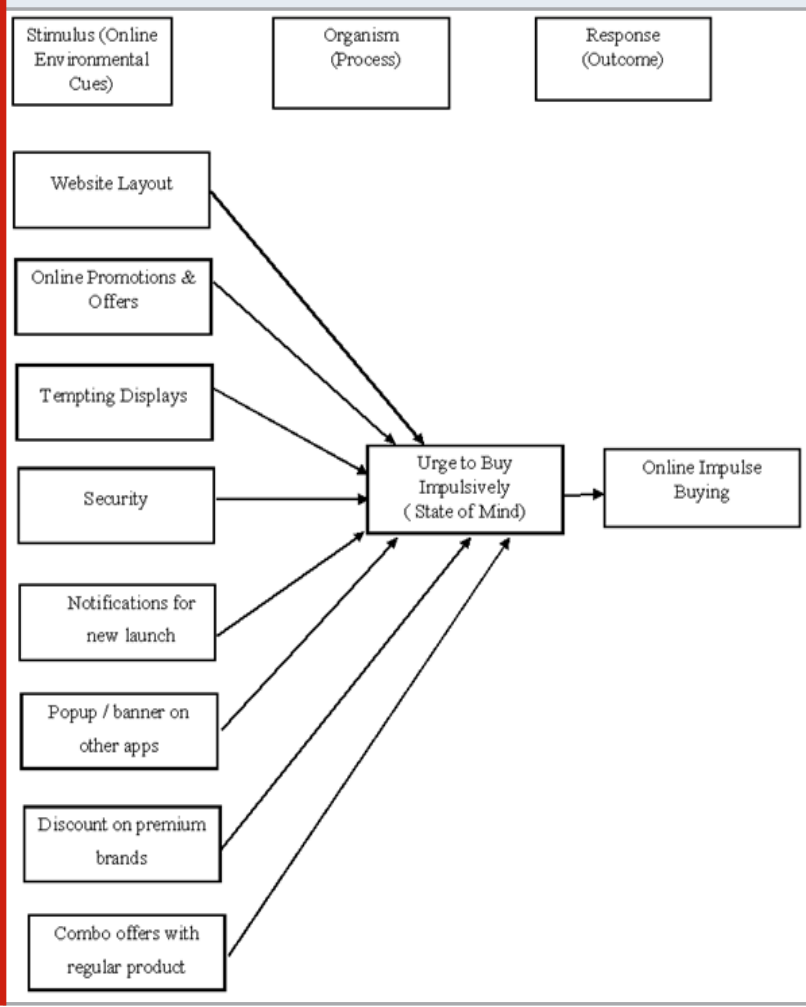

\section{FINDINGS \&t DISCUSSION}

The review along with the focus group conducted suggests that buying impulsively online or the urge consumers get to buy online are two elements that lead to actual buying of grocery. The parameters that entail within these elements are hedonism in terms of pleasure one derives to buy online, apart from the atmosphere of the website, its layout, the security features, privacy of the transactions, the trust factor that consumers gain after repeated purchases apart from discounts and promotional offers that need to be studied more. Online Impulse Buying of Grocery Products is a phenomenon that is yet to be explored more in terms of the factors that propel consumers to buy online. Though online grocery shopping has been rampant in the past 5 years in India, eliciting accurate information would require more detailed quantitative study. The researchers studied effects of two types of sales promotion commonly known to marketers as price discounts and bonus cartons and discount on premium brands.

Previous researchers have shown that bonus as a tool of promotion has a greater impact on offline impulse buying than price discounts. However, our findings were different in the online context dealing with grocery shopping in which price discounts were primarily the reason to buy groceries on impulse that resulted in higher impulse buying intention than bonus as promotional techniques when the product was hedonic and where pleasure seeking was one of the main reasons behind buying impulsively whereas bonus were a more effective sales promotion than price discounts when the product was practical. The utilitarian value was highlighted in search transactions. In addition, price discounts as tool garnered more impulse buying intention than bonus as a tool when the product was inexpensive, whereas bonus was a more effective marketing promotion method than were price discounts when the product was expensive.

\section{CONCLUSION}

The S-O-R framework is a unique theoretical concept which is instrumental in understanding the consumers behavior while shopping online. The review suggests that urge to buy impulsively can be propelled by various stimuli to the consumers which would inadvertently make the consumers buy impulsively online. The focus groups conducted in the suburbs of Mumbai and Pune City cite various stimuli which leads to impulse buying of grocery products. Price discounts, bonus packs, discounts on premium brands, tempting displays, traditional dishes online, pop up banners, video content, online promotion, content are some of the stimuli that can effectively work with the cognitive and affective state of minds thus propelling the consumers to indulge into a positive behavioural response and make them buy grocery impulsively online. The researchers with an ardent hope aim to explore more into this phenomenon of buying grocery impulsively online by extending the review into a more robust empirical survey amongst consumers who buy grocery online.

\section{REFERENCES}

Arora, R. (1982). Validation of an SOR model for situation, enduring, and response components of involvement. Journal of Marketing Research, 19(4), 505-516.

Bitner, M.J. (1992) Servicescapes: The Impact of Physical Surroundings on Customers and Employees. Journal of Marketing, 56, 57-71.

Buckley, P. G. (1991). An SOR model of the purchase of an item in a store. Advances in Consumer Research, 18(1), 491-500.

Chang, H. H., \&t Chen, S. W. (2008). The impact of 
online store environment cues on purchase intention Trust and perceived risk as a mediator. [Article]. Online Information Review, 32(6), 818-841.

Childers, T.L., Carr C.L., Peck J., and Carson S. (2001), "Hedonic and utilitarian motivations for online retail shopping behavior”, Journal of Retailing, Vol. 77, 2001, pp.511-535.

Demangeot, C., \&t Broderick, A. (2007). Conceptualising consumer behaviour in online shopping environments. International Journal of Retail \& Distribution Management, 35(11), 878-894.

Donovan, R. J., \&t Rossiter, J. R. (1994). Store atmosphere and purchasing behavior. Journal of Retailing, 70(3), 283-294

Eroglu, S. A., Machleit, K. A., \&t Davis, L. M. (2001). Atmospheric qualities of online retailing: A conceptual model and implications. Journal of Business Research, 54(2), 177-184.

Eroglu, Sevgin \& Machleit, Karen \&t Davis, Lenita. (2003). Empirical Testing of a Model of Online Store Atmospherics and Shopper Responses. Psychology and Marketing. 20. 139 - 150.

Ezeh, C. and Harris, C.L. (2007): Servicescape research: A review and a research agenda. Marketing Review 7(1),59-78.

Jacoby, J. (2002). Stimulus-Organism-Response Reconsidered: An Evolutionary Step in Modeling (Consumer) Behavior. Journal of Consumer Psychology ,12(1),51-57.

Kim, H., \& Lennon, S. J. (2010). E-atmosphere, emotional, cognitive, and behavioral responses. Journal of Fashion Marketing and Management, 14(3), 412-428.

Kotler, Philip. (1973). Atmospherics as a Marketing Tool. Journal of Retailing. 49.

Lazarus, R. S. (1998). Fifty years of research and theory by RS Lazarus: an analysis of historical and perennial issues: Lawrence Erlbaum.

Loureiro, Sandra \& Ribeiro, L.. (2011). The Effect of Atmosphere on Emotions and Online Shopping
Intention.

Manganari, E. E., Siomkos, G. J., \&t Vrechopoulos, A. P. (2009). Store atmosphere in web retailing. European Journal of Marketing, 43(9-10), 1140-1153.

Mehrabian, A., \& Russell, J. A. (1974). An approach to environmental psychology: the MIT Press

Mollen, A. and Wilson, H. (2010) Engagement, Telepresence and Interactivity in Online Consumer Experience: Reconciling Scholastic and Managerial Perspectives. Journal of Business Research, 63, 919925.

Morganosky, Michelle \& Cude, Brenda. (2000). Consumer Response to Online Grocery Shopping. International Journal of Retail \& Distribution Management. 28. 1726.

Novak, Thomas \& Hoffman, Donna \&t Yung, Yiu-Fai. (2000). Measuring the Customer Experience in Online Environments: A Structural Modeling Approach. Marketing Science. 19. 22-42.

Olney, Thomas \& Holbrook, Morris \& Batra, Rajeev. (1991). Consumer Responses to Advertising: The Effects of Ad Content, Emotions, and Attitude Toward the Ad on Viewing Time. Journal of Consumer Research. 17. 440-53

Prashar, Sanjeev \&t Vijay, T. \&t Parsad, Chandan. (2017). Effects of Online Shopping Values and Website Cues on Purchase Behaviour: A Study Using S-0-R Framework. Vikalpa. 42. 1-18.

Ramus, K. and Nielsen, N. A. (2005). Online grocery retailing: What do consumers think? Internet Research, 15(3), 335-352.

Rose, Susan \& Clark, Moira \&t Samouel, Phillip \& Hair, Neil. (2012). Online Customer Experience in e-Retailing: An empirical model of Antecedents and Outcomes. Journal of Retailing. 88. 308-322.

Wakefield, K., \&t Blodgett, J. (1996). The effect of the servicescape on customers' behavioral intentions in leisure service settings. Journal of Services Marketing, 10(6), 45-61 